\title{
TEXTURAL ANALYSIS THROUGH THICKNESS OF API X70 STEEL AFTER HOT ROLLING AND POST HEAT TREATMENT*
}

\author{
Mohammad Masoumi ${ }^{1}$ \\ Hamilton Ferreira Gomes de Abreu ${ }^{1}$
}

\begin{abstract}
In the present study, API 5L X70 pipeline steel samples were deformed by hot-rolling cooled in air or quenched in water and subsequently tempered at different temperatures. X-ray diffraction (XRD) and electron backscatter diffraction (EBSD) technique were used to analyze the texture evolution from the initiate state to rolling and tempering state at mid-thickness and near surface plane of all samples. The results showed that the mid-thickness region is richer in $\{100\} / / N D$ oriented grains known as more susceptible to crack formation and growth through. Hot deformed specimen showed dynamic recrystallization grains while quench tempered sample at $700^{\circ} \mathrm{C}$ evidenced recovery and grain growth.
\end{abstract}

Keywords: API-X70 steel, Hot rolling, EBSD. 


\section{INTRODUCTION}

Recently, the use of pipeline steels to transport sour media gas has increased due to exhaustion of natural sweet gas [1]. However, mechanical properties of this high strength steels can be degraded by exposure to hydrogen on sour gas environment. Their surfaces corrode and produce hydrogen that can be absorbed in the steel. Hydrogen diffusion starts on stress concentration regions, promoting brittle behavior (hydrogen embrittlement) and ductility damage [2]. On sour-service steels, the resistance to hydrogen damage has been improved through sulphur content reduction, inclusion morphology control, and use of low segregated uniform microstructures. These strategies have not proven to be totally effective for severe operating conditions [3]. However, the crystallographic texture control and grain boundary distribution have recently been proposed as a mean to further reduce the susceptibility to hydrogen damage.

Due to the centerline segregation of alloying elements during casting, the cracks concentrate on the mid-thickness [1]. Since the centerline is a final solidification zone during continuous casting, solute atoms concentrate on this region because their solubility in liquids is higher than in solids. Therefore, the mid-thickness region has large concentration of alloying elements than surface region, which results in big particle formations that can facilitate the hydrogen embrittlement.

During rolling, a residual stress induced by shear deformation is formed near surface region because of friction between rolls and plate surface. This residual stress and shear strain across thickness generate significant improvements in crack formation resistance near surface region, forming $\{110\} / / N D$ and $\{111\} / / N D$ texture fibers [4].

Since API X70 steels are produced by different thermo-mechanically controlled processes (TMCP), wide range microstructures can result, depending on the actual processing conditions. Consequently, the microstructure, grain size, volume fraction of inclusions and precipitates, and dislocation density can vary within a particular strength grade [5]. Moreover, deformation-induced through-thickness (texture inhomogeneity) is a well-known phenomenon that affects texture evolution through thickness reduction during rolling [6, 4]. Ray et al. [7, 8] showed that warm rolling could be used to produce steel with textures dominated $b\{112\} / / N D,\{111\} / / N D$, and $\{011\} / / N D$ fibers.

In previous paper [4] showed that controlled rolling schedules can induce crystallographic textures dominated by the $\{112\} / / N D,\{111\} / / N D$, and $\{011\} / / N D$ fibers near surface regions. These texture components decrease significantly the susceptibility to crack nucleation and propagation, as a result of the reduction in number of available transgranular and intergranular low resistance cleavage paths provided by the $\{001\} / / N D$ oriented grains. As a consequence, the main goal of this paper is to analyse particular aspects of texture inhomogeneity during TMCP, specifically, the formation of texture gradients across thickness reduction during hot rolling and post heat treatment, which are partly inherited in the subsequent recrystallization processes.

Electron backscatter diffraction (EBSD) technique analysis was used to analyse microtexture components near surface and mid-thickness layers of each studied specimen, where different crystallographic textures and grain-boundary distributions were found. These results support the hypothesis about the possibility of improving mechanical properties and crystallographic through texture control by hot rolling with post heat treatment, thus reducing consequently the susceptibility of pipeline steels to hydrogen damage. 


\section{MATERIAL AND METHODS}

The starting material was an API-X70 steel, available in the form of rolled plate with $8.5 \mathrm{~mm}$ thickness. Table 1 shows the chemical composition of the as-received API X70 steel (called as sample a) used in this study. Strips of the starting material were rolled at $1000^{\circ} \mathrm{C}$ and cooled with two different ways: one was cooled in air (called as sample b) and two others were quenched in water followed by a tempering treatment. One was treated at $350^{\circ} \mathrm{C}$ and other at $700^{\circ} \mathrm{C}$ for one hour (they are called as sample $\mathrm{c}$ and sample $\mathrm{d}$, respectively).

Table 1. Chemical analysis obtained by emission spectrometry technique of API X70 (in wt \%).

\begin{tabular}{ccccccccccccc}
\hline $\mathrm{C}$ & $\mathrm{Si}$ & $\mathrm{Mn}$ & $\mathrm{S}$ & $\mathrm{Al}$ & $\mathrm{Cu}$ & $\mathrm{Cr}$ & $\mathrm{P}$ & $\mathrm{Ni}$ & $\mathrm{Mo}$ & $\mathrm{Nb}$ & $\mathrm{Ti}$ & $\mathrm{V}$ \\
\hline 0,099 & 0,258 & 1,664 & 0,005 & 0,04 & 0,014 & 0,021 & 0,018 & 0,022 & 0,816 & 0,061 & 0,02 & 0,050 \\
\hline
\end{tabular}

Macrotexture measurements have been carried out along the RD-TD sections in two specific regions: at mid-thickness and near surface layer. It was made with the purpose of evaluating the texture non-homogeneity across thickness reduction. Three incomplete pole figures ( $\{110\},\{200\}$, and $\{211\})$ were measured using a Co goniometer. Using the M-text tool box, the orientation distribution function (ODF) was determined for each sample from their measured pole figures. The Bunge's Euler angles were adopted to describe orientations and the $\varphi_{2}=45^{\circ}$ section of Euler space was used to display the computed ODFs.

Microtexture analyses were performed by EBSD technique on an Oxford Channel 5EBSD system attached to a scanning electron microscope Philips ${ }^{\circledR}$ XL-30. Scans of $400 \times 120 \mu \mathrm{m}$ were carried out at two regions of each specimen: near surface and mid-thickness with $0.5 \mu \mathrm{m}$ step size. All texture measurements were performed on the plane perpendicular to the transverse direction (TD) of each specimen. The specimen surfaces were mechanically polished with silicon carbide paper from grade 100 to grade 1200, followed by polishing with diamond paste $(6,3$ and $1 \mu \mathrm{m})$, and finally, polished with $0.05 \mu \mathrm{m}$ colloidal silica slurry for $3 \mathrm{~h}$.

The EBSD components can measure and calculate the internal average misorientation angle within each grain, then evaluate the deformation level in the following way [13]: the calculated internal average misorientation angle is compared with a minimum misorientation angle to define a subgrain, $\theta_{c}$. If the average grain angle exceeded the defined minimum angle $\left(\theta_{c}=2^{\circ}\right.$ in this case), then the grains were classified as "deformed." If the grains consisted of subgrains whose internal misorientation was under $\theta_{c}$ but the misorientation from subgrain to subgrain was above $\theta_{c}$, the grain was classified as "substructured" and the remainder grains were classified as "recrystallized." Thus three different levels of deformation can be classified in the scanned grains, "deformed" (highest deformation), "substructured" (medium deformation) and "recrystallized"(lowest deformation). It can be shown on EBSD map by three different colors, red, yellow and blue respectively.

\section{RESULTS AND DISCUSSION}

\subsection{Macrotexture Study}

Figure 1 shows the orientation distribution function (ODF at $\varphi_{2}=45^{\circ}$ section) calculated from pole figures measured by XRD for all studied specimens at both regions: mid-thickness and near surface. The texture representation in terms of 
orientation distribution function (ODF) revealed that the texture of starting material is practically homogenous that is a common type of hot deformation texture. Starting material contains dominant $\{001\} / / N D$ and $\{111\} / / N D$ fibers and intense (001)[110] (rotated cube) and (112)[110] components. The (001)[110] component is introduced when austenite grains were formed during and at the end of rolling due to partial recrystallization [8].

After hot-rolling, at mid-thickness, texture intensities were reduced. The tempering treatment at $350^{\circ} \mathrm{C}$ of deformed samples (sample c) generated further texture intensity reduction; their $\mathrm{Y}$-fiber $(\{111\} / / N D)$ was dominated by (111)[121] and (111)[112] $\left(\varphi_{1}=30\right.$ and $90^{\circ}, \varnothing=55^{\circ}, \varphi_{2}=45^{\circ}$, respectively). Meanwhile, a tempering treatment at $700^{\circ} \mathrm{C}$ (sample d) generated (110)[331] $\left(\varphi_{1}=12^{\circ}, \varnothing=90^{\circ}, \varphi_{2}=45^{\circ}\right)$ texture component.

At mid-thickness region, texture component showed different behaviors due to residual shear strain induced by friction between rolls and strip. Surprisingly, during hot-rolling, a $\{110\} /$ ND fiber was developed and the intense of Goss texture ((110)[001]) was highlighted among its fiber components. After tempering treatments, texture intensity increased gradually whit tempering temperature. Thus, high temperature treatment (sample d) generated intense (110)[111], (110)[112] and (110)[001] components placed in $\varphi_{1}=35,55$ and $90^{\circ}, \emptyset=90^{\circ}, \varphi_{2}=45^{\circ}$, respectively.

\subsection{Microtexture Study}

Fig. 2 shows the inverse pole figure (IPF) maps obtained by EBSD at both regions: near surface and mid-thickness region of all specimens. In order to achieve a better estimation of the bulk samples, EBSD measured were analyzed on large areas. Their grain numbers and grain sizes were calculated and listed in table 2.

Table 2: Grain number and grain sizes of all specimens at both regions.

\begin{tabular}{|c|c|c|c|c|}
\hline \multirow{2}{*}{ Sample } & \multicolumn{2}{|c|}{ Center Plane } & \multicolumn{2}{|c|}{ Near Surface Plane } \\
\hline & Grain number & Diameter $\mathrm{d}[\mu \mathrm{m}]$ & Number of Grains & Diameter $\mathrm{d}[\mu \mathrm{m}]$ \\
\hline a & 759 & $6,2 \pm 0.5$ & 380 & $8,9 \pm 0.5$ \\
\hline b & 2467 & $4,1 \pm 0.5$ & 2100 & $4,2 \pm 0.5$ \\
\hline c & 4041 & $2,8 \pm 0.5$ & 4039 & $2,8 \pm 0.5$ \\
\hline$d$ & 435 & $9,0 \pm 0.5$ & 650 & $7,8 \pm 0.5$ \\
\hline
\end{tabular}

It is worth mentioned that during hot rolling and cooling in air, only a few grains displayed abnormal growth in both regions of rolled sample: near surface and midthickness region. Thus, fine and coarse grains coexist in the microstructure. Most grains are slightly elongated, predominantly forming clusters aligned with the rolling direction (RD). Abnormally grown grains are rare in this material as a result of participle pinning and solute drag effects.

According to Fig. 2 and Table 2, the starting material showed a grain size about $9 \mu \mathrm{m}$ mixed with some fine grains at mid-thickness region and the grain size of sample $b$ and $c$ at both studied regions are relative homogeneous. During hot rolling, the grain size remarkable shifted to finer grains, generating large fractions of $4 \mu \mathrm{m}$ grain size on both regions. However, hot-rolled sample followed by quenched in water and tempered at $350{ }^{\circ} \mathrm{C}$ (sample c) evidenced a significant grain size reduction. The deformed sample tempered at $700^{\circ} \mathrm{C}$ (sample d) developed recovery, recrystallization and grain growth phenomenon. Therefore, coarse grains were 
revealed in both studied regions, but mid-thickness region presented larger grain sizes than near surface layer.
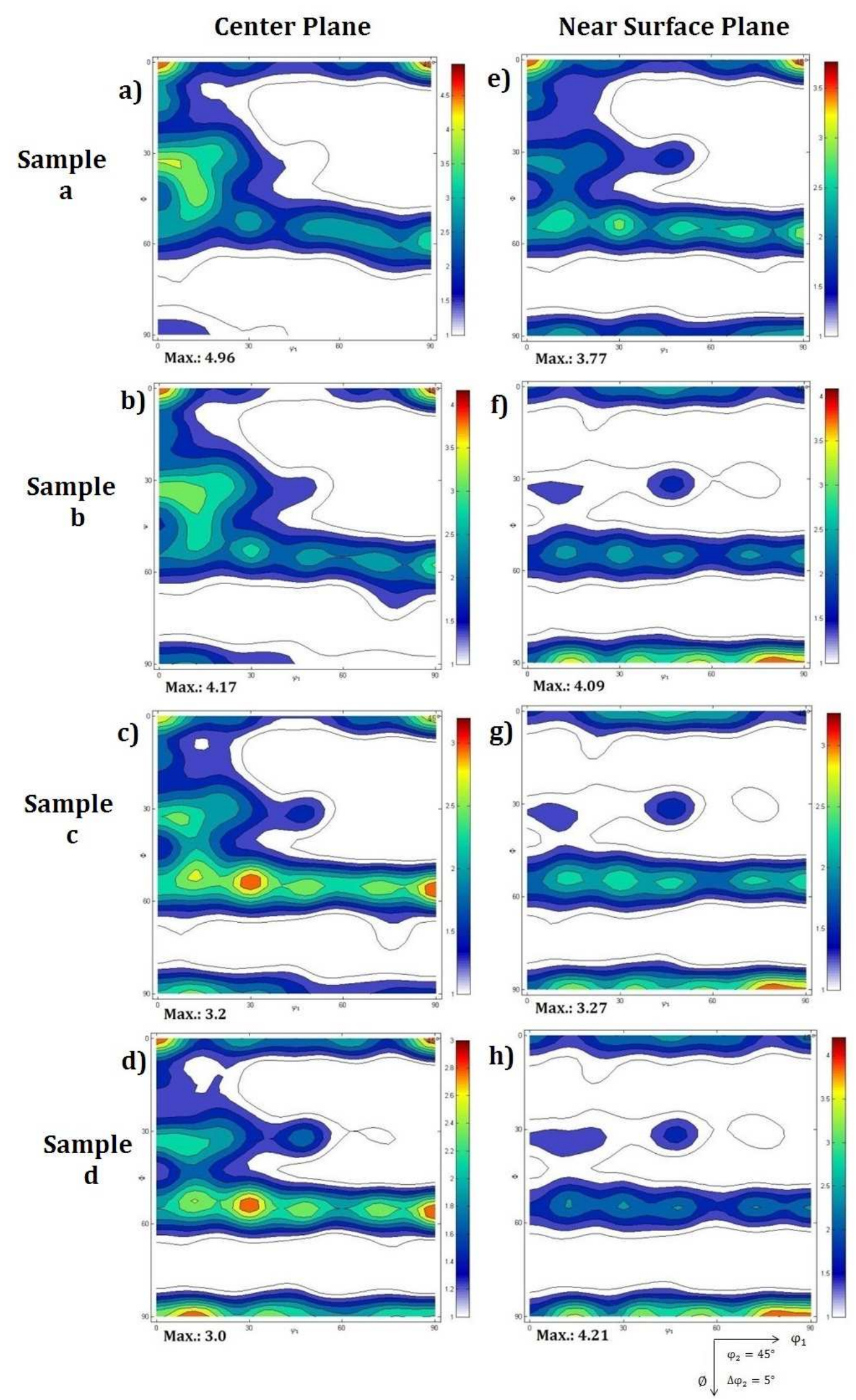

Figure 1. Texture representation in terms of orientation distribution function (ODF in $\varphi 2=45^{\circ}$ section) at mid-thickness and near surface of all specimens. 
Since fine grains provide larger grain boundaries, reducing the mobility of hydrogen entrapment, and pile up dislocations at nodes or triple junctions, the hydrogen diffusion and dislocation densities decrease through grain boundaries. It implies that a large grain provides a main free path for hydrogen, increasing the hydrogen diffusion. Nonetheless, the effect of grain size on crack formation is still a challenging issue; it would be in agreement that cracks can be propagated along fine grains.

\section{Center Plane}

a)
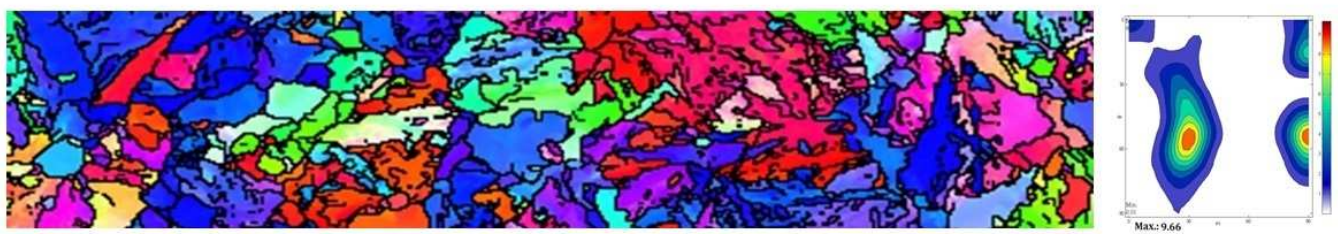

b)

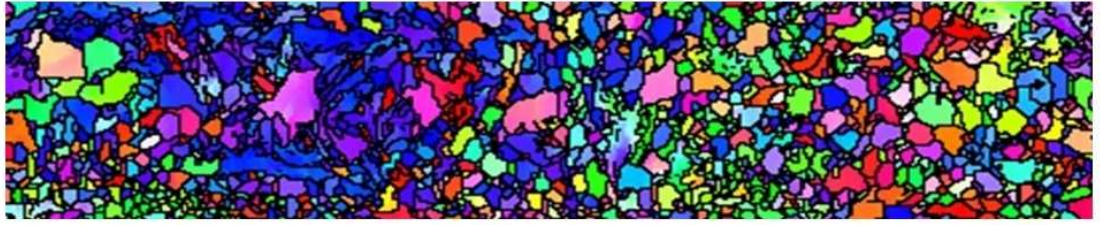

c)

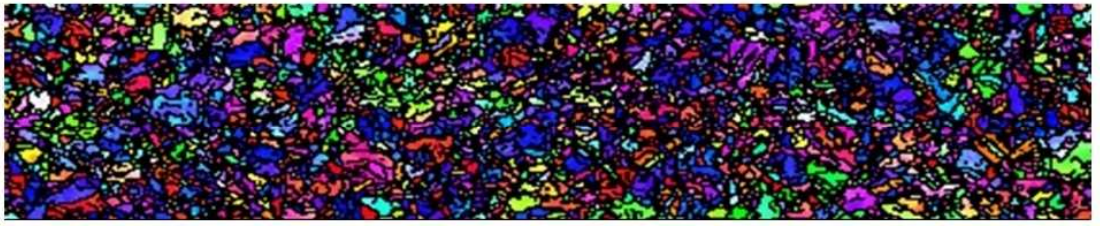

d)
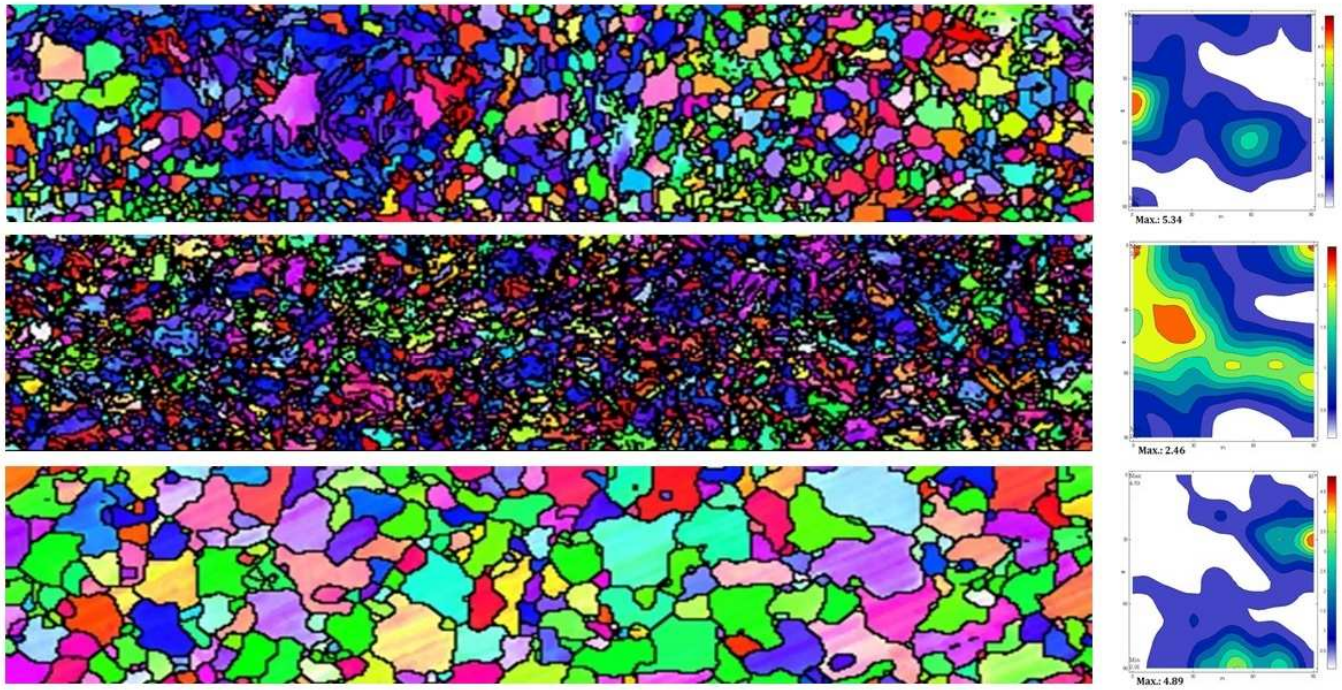

\section{Near Surface Plane}

e)
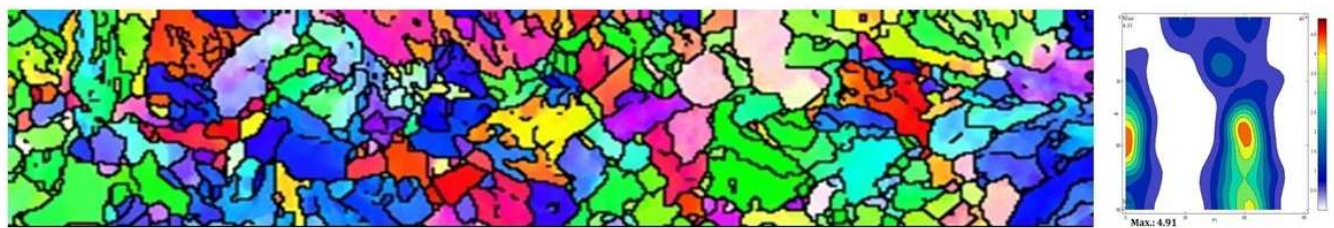

f)
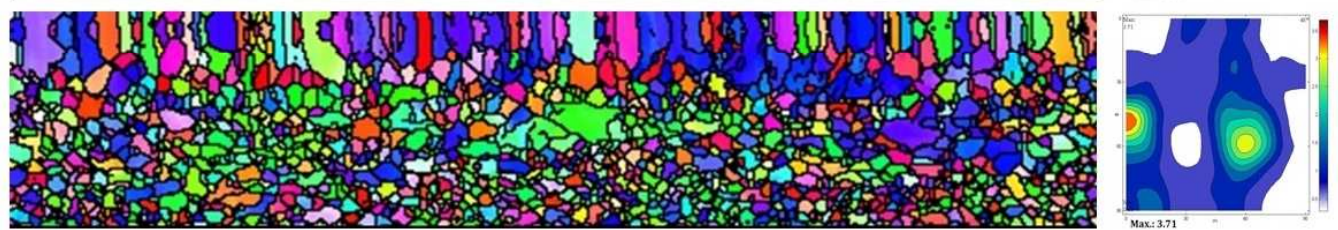

g)
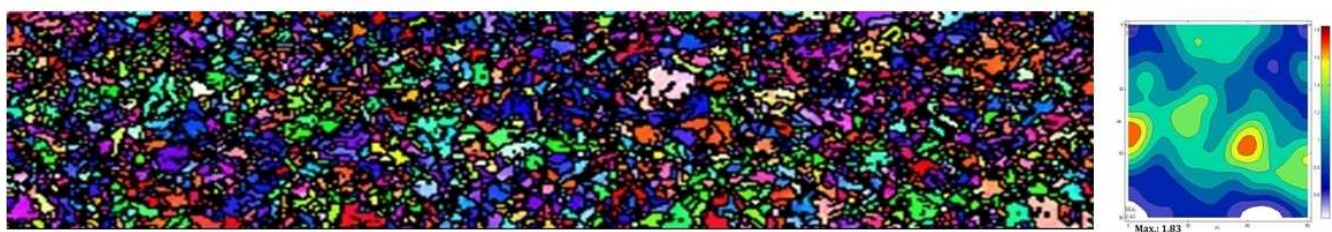

h)
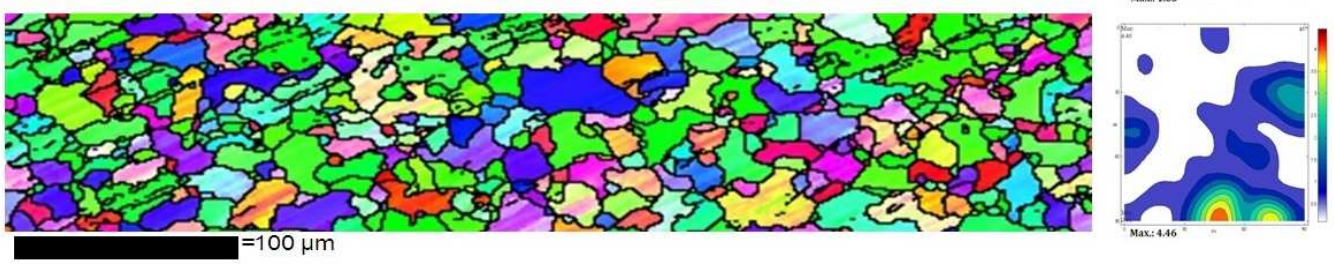

Figure 2: IPF color maps of all specimens at both regions: mid-thickness and near surface layers. $(a, e)$ sample a, $(b, f)$ sample b, $(c, g)$ sample $c$ and $(d, h)$ sample $d$. 
Ichimura et al. [10] proposed that grain boundaries have two kinds of effect on hydrogen mobility: the fast one enhances hydrogen diffusion along grain boundaries of large grains. The other one suppress diffusion by trapping hydrogen atoms at grain boundary nodes, which might be remarkable for small grains. Besides, Ayesha et al. [5] found that API X70 steel strips with similar grain sizes on both regions: surface and mid-thickness layer exhibited similar hydrogen diffusivities, whereas standard API X70 samples with different grain sizes on each region showed a lower diffusivity on surface than that of the mid-thickness region owing to the combination of fine grains and high dislocation density.

Since grain boundaries can act as obstacles to dislocation motion/crack propagation, depending on the boundary nature and plastic deformation leads to pile-up of dislocations in front of boundaries, different stress concentrations are introduced on certain grain boundaries and on their adjacent grain [11]. When the stress concentration is high enough to reach the critical value, a dislocation source is activated in adjacent grains and plastic deformation can spread out into those grains, increasing resistance and hardness of deformed material [12] On the other hand, it is known that there is a linear correlation between hydrogen damage susceptibility and hardness value in steels. Therefore, the fine grains formed during hot rolled and quench tempered samples make this steel more prone to crack formation.

Inverse pole figure (IPF) maps of all specimens at both studied regions were represented in terms of orientation distribution function (ODF in $\varphi_{2}=45^{\circ}$ section) and are shown in figure 2. Although, it is worth mentioning that (IPF) maps has been analyzed on small regions. This microtexture could not represent the crystallographic orientations of whole samples; meanwhile it provide valuable and attributable information to better understanding the texture evaluation during hot deformation and post heat treatments.

According to ODF generated from inverse pole figure (IPF) maps (Fig 2), starting material had a dominated texture component of (111)[121] (at $\varphi_{1}=30$ and $90^{\circ}, \varnothing=55^{\circ}, \varphi_{2}=45^{\circ}$ )on mid-thickness region. During hot rolling (sample b), $\{001\}$ and \{111\}//ND fibers and (223)[110] and (111)[011] were formed as predominant components. Quenched sample formed (001)[110]component (rotated cube), which is known as a preferred crystallographic orientation to crack nucleation and (112)[uvw] components as slip activator. Finally, (223)[212] and (110)[112] components were formed during recovery ( sample d).

Near surface, $\{111\}$ and $\{110\} / / N D$ fibers were developed significantly due to shear strain introduced during rolling. The (111)[011] texture component commonly is developed during recrystallization in the API steel production. Samples b and c showed the same dominant texture components and $y$-fiber. As to be expected, dominant (110)[112] Brass component and (110)[113] were generated in this region.

Figure 3 shows maps containing the recrystallized, substructured and deformed fractions generated near surface and mid-thickness of all studied specimens. These areas were identified according to misorientations presented in each grain. In this sense, it can be seen that the recrystallized fraction increased during hot deformation in both near surface and mid-thickness region.

In general, mid-thickness of all specimens showed large number of deformed grains scattering located, meanwhile the whole quench tempered specimen was found to be almost totally deformed. Interestingly, hot rolled specimen showed the largest recrystallized grain fraction in both regions. It was developed because dynamic recrystallization happened during hot-rolling, and the bainite was dissociated to partial deformed ferrite, then the formed austenite was transformed to upper bainite 
by cooling in air. Meanwhile, bainite laths were merged into larger ones in the subsequent tempering, relaxed strain and deformation [13].

Center Plane

a)

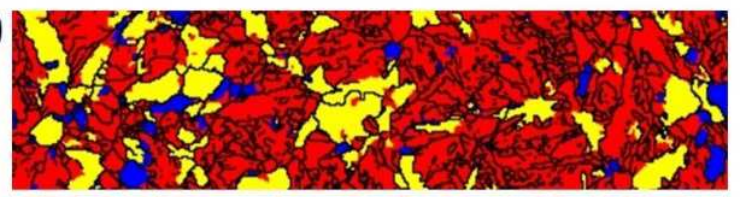

b)

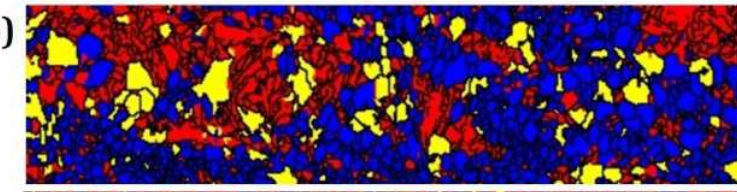

c)

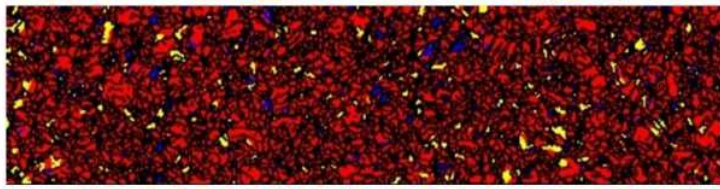

d)

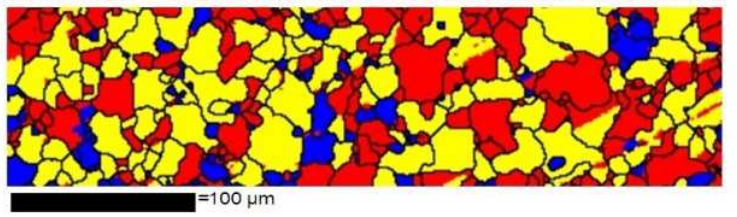

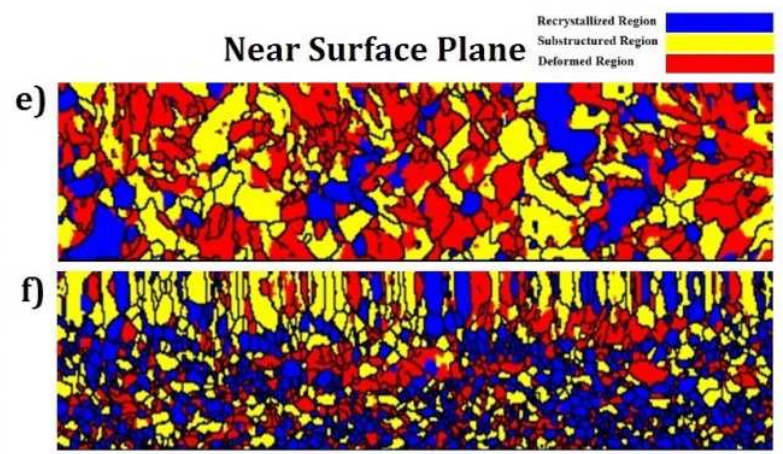

g)

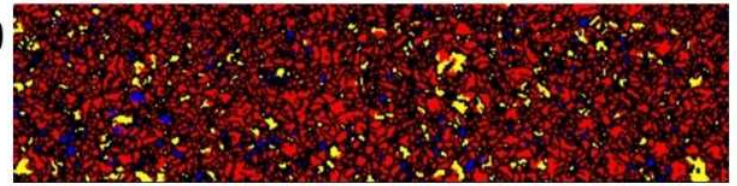

h)

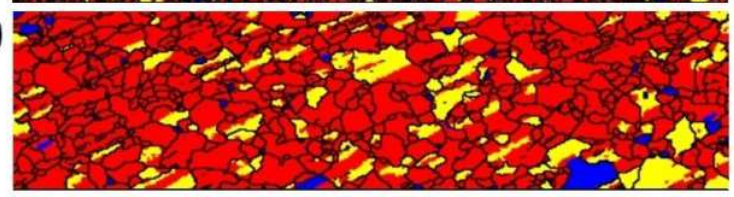

Figure 3: EBSD recrystallization fraction map at $(a, e)$ as-received material, $(b, f)$ hot rolled, $(c, g)$ quench tempered at $350^{\circ} \mathrm{C}$ and $(\mathrm{d}, \mathrm{h})$ quench tempered at $700^{\circ} \mathrm{C}$ after hot rolling.

The strength and hardness considerably decreased by recrystallization process, where the deformed grains are replaced by a new set of strain free grains. These recrystallized grains have a higher resistance to plastic deformation and crack formation. Moreover, dynamic recrystallization commonly forms $\{110\}$ and $\{111\} / / N D$ texture component during hot-rolling and it is known that a dominant $\{111\} / / N D$ texture increases crack formation resistance in pipeline steel $[13,14]$.

The volume fraction of grains with $<111>$ orientation increased with the recrystallized grain fractions. A dislocation density reduction and the new recrystallized grains have an effective impact on improving crack formation resistance.

It is notable that recrystallized grains were preferentially produced in the midthickness region. It can be attributed to the high stored strain energy and different texture formed in both regions: on the surface and in the mid-thickness of tested sheets. The stored strain energy was higher on mid-thickness region than surface so that it provided higher driving force and resulted in a full recrystallization [14].

In the recovery process, the deformed grains reduce their stored energy. Since the dislocation density is very high in deformed grains, they are prone to crack formation. The recrystallized fraction in sample b observed to be the highest. Interestingly, the substructured regions in the quench tempered specimen have the lowest fraction near surface area while its area fraction in the mid-thickness region is the highest ones. Also the deformed area near surface of the quench tempered specimen has the highest fraction while in mid-thickness region of as-received material is high compared with the others. Therefore, one may conclude that the sample $b$ has a lower stored energy and can therefore resist more against cracking, in contrast, quench tempered material has a higher stored energy and it is so prone to crack formation. In addition, the deformed fraction area of grains at center layer is higher than near surface one so it could be conclude the center area is more susceptible for crack formation in compared of near surface area. As a result, the deformation is 
more concentrated in the center region of specimens. Also, the dislocation density in the sample $\mathrm{c}$ is highly higher than the other specimens at both center and near surface layers. Dislocations are recognized as reversible hydrogen traps that keep hydrogen for a limited time and make the steel more fragile. Therefore, the crack propagates through the grains that provide very easy path for the growth which is seen in the specimen. Since the stored energy of deformed grains is very high, the crack tends to propagate along these types of grains. The possibility is that the crack nucleation and propagation through the deformed grains after hot rolling and quenched in water because of absence of occurrence the recrystallization or recovery during it process. However, it is more likely that the crack initiated and propagated through several deformed grains and other grains were deformed during the crack growth.

\section{CONCLUSIONS}

These suggested thermomechanical processes are well-known and easy to implement in the steel industry. They lead to a crystallographic texture dominated by the $\{111\} / / N D$ fibre near surface plane.

- It is expected to reduce significantly the probability of crack formation by reducing the $\{001\} / / N D$ oriented regions

- The deformed fraction grains in quenched tempered specimens was significantly high, it makes the sample very fragile and prone to crack formation. In contrast, in hot deformed specimen with high amount of recrystallization fraction with no stored energy is one reason for high crack formation resistance.

It may also decrease the probability of crack formation during hot deformation due to reduce in plastic deformation fraction in specimen.

\section{Acknowledgments}

The authors would like to appreciate the help of the research board of the Universidade Federal do Ceará for the financial support and Laboratório de Caracterização de Materiais (LACAM) for provision of research facilities of this work.

\section{REFERENCES}

1 Joonoh Moon, Chulbong Park, Seong-Ju Kim. Influence of Ti Addition on the Hydrogen Induced Cracking of API 5L X70 Hot-Rolled Pipeline Steel in Acid Sour Media. Met. Mater. Int., Vol. 18, No. 4 (2012), pp. 613 617.

2 Ayesha J. Haq, K. Muzaka, D.P. Dunne, A. Calka, E.V. Pereloma. Effect of microstructure and composition on hydrogen permeation in X70 pipeline steels. International journal of hydrogen energy 38(2013) 2544 e 2556.

3 Cesar R.F. Azevedo. Failure analysis of a crude oil pipeline. Engineering Failure Analysis 14 (2007) 978-994

4 Mohammad Masoumi, Hamilton Ferreira Gomes de Abreu. Study of Texture and Microstructure Evaluation of Steel API 5L X70 under Various Thermomechanical Cycles.

$5 \mathrm{~J}$ G Williams. Advances in steels for high strength ERW linepipe application in Australia. Materials forum volume $31-2007$.

6 B. Sander, D. Raabe. Texture inhomogeneity in a Ti-Nb-based $\beta$-titanium alloy after warm rolling and recrystallization. Materials Science and Engineering A 479 (2008) 236247.

7 A. Haldar, R.K. Ray. Microstructural and textural development in extra low carbon steel during warm rolling. Materials Science and Engineering A 391 (2005) 402-407 
8 A. Haldar, X. Huang, T. Leffers, N. Hansen, R.K. Ray. Grain orientation dependence of microstructures in a warm rolled IF steel. Acta Materialia 52 (2004) 5405-5418

9 Jinxing Jiang, Huibin Wu, Jinming Liang ,Di Tang. Microstructural characterization and impact toughness of a jackup rig rack steel treated by intercritical heat treatment. Materials Science \& Engineering A587(2013)359-364.

10 Minoru Ichimura, Yasushi Sasajima, Mamorou Imabayashi. Grain Boundary Effect on Diffusion of Hydrogen in Pure Aluminum. Materials Transactions, JIM, Vol. 32, No. 12 (1991), pp. 1109 to 1114.

11 N.J. Petch. The cleavage strength of polycrystals. J. Iron Steel Inst. 174:25-8, 1953.

12 Duber, B. Kunkler, U. Krupp, H.-J. Christ, C.-P. Fritzen. Experimental characterization and two-dimensional simulation of short-crack propagation in an austenitic-ferritic duplex steel. International Journal of Fatigue 28 (2006) 983-992.

13 M.A. Arafin, J.A. Szpunar. A new understanding of intergranular stress corrosion cracking resistance of pipeline steel through grain boundary character and crystallographic texture studies. Corrosion Science 51 (2009) 119-128

14 M.A.Mohtadi-Bonab, M.Eskandari, J.A.Szpunar. Texture, local misorientation, grain boundary and recrystallization fraction in pipeline steels related to hydrogen induced cracking. Materials Science\&EngineeringA620(2015)97-106. 